University of Nebraska - Lincoln

DigitalCommons@University of Nebraska - Lincoln

Faculty Papers and Publications in Animal

Science

Animal Science Department

4-30-2007

\title{
Across-breed adjustment factors for expected progeny differences for carcass traits
}

L. Dale Van Vleck

University of Nebraska-Lincoln, dvan-vleck1@unl.edu

L. V. Cundiff

USDA, ARS

T. L. Wheeler

USDA-ARS, tommy.wheeler@ars.usda.gov

S. D. Shackelford

USDA, ARS

M. Koohmaraie

USDA, ARS

Follow this and additional works at: https://digitalcommons.unl.edu/animalscifacpub

Part of the Animal Sciences Commons

Van Vleck, L. Dale; Cundiff, L. V.; Wheeler, T. L.; Shackelford, S. D.; and Koohmaraie, M., "Across-breed adjustment factors for expected progeny differences for carcass traits" (2007). Faculty Papers and Publications in Animal Science. 121.

https://digitalcommons.unl.edu/animalscifacpub/121

This Article is brought to you for free and open access by the Animal Science Department at DigitalCommons@University of Nebraska - Lincoln. It has been accepted for inclusion in Faculty Papers and Publications in Animal Science by an authorized administrator of DigitalCommons@University of Nebraska - Lincoln. 


\title{
Across-breed adjustment factors for expected progeny differences for carcass traits ${ }^{1}$
}

\author{
L. D. Van Vleck, $\uparrow^{2}$ L. V. Cundiff, $\ddagger$ T. L. Wheeler, $\$$ S. D. Shackelford, $\ddagger$ and M. Koohmaraie $\ddagger$ \\ USDA, ARS, Roman L. Hruska US Meat Animal Research Center, \\ $\dagger$ Lincoln, NE 68583-0908 and †Clay Center, NE 68933
}

\begin{abstract}
Adjustment factors to allow comparison of EPD from several breed associations for birth, weaning, and yearling weights have been available for more than $10 \mathrm{yr}$. This paper describes steps to calculate adjustment factors for EPD for 4 carcass traits: marbling score, fat thickness, ribeye area, and retail product percentage. The required information is the same as for the weight traits: 1) breed of sire solutions based on measurements on progeny at the US Meat Animal Research Center (USMARC) that have sires with breed association EPD, 2) mean EPD of sires weighted by number of progeny at USMARC (USMARC progeny not included in breed association EPD), and 3) mean EPD of nonparents from breed associations (defined as animals born $2 \mathrm{yr}$ prior to calculation of EPD). Records at USMARC are adjusted to $100 \%$ heterozygosity because the purpose of the adjustment factors is to allow prediction of performance of progeny of sires mated to other breeds of dam. A critical step is to adjust breed of sire solutions,
\end{abstract}

which are based on an earlier sample of sires, to the equivalent of a sample from a more recent nonparent group using the difference between mean EPD from information sources 2) and 3). The difference is multiplied by the coefficient of regression of USMARC progeny on EPD of their sires. With weight traits, these coefficients are not greatly different from unity. With the carcass traits, 2 sets of coefficients can be used depending on whether the EPD are based on carcass or ultrasound measurements. The regression coefficients also reflect differences in conditions for USMARC progeny (all steers) and factors associated with breed association EPD. Only for marbling score and ribeye area were any estimates of the regression coefficients near unity. For other traits, the coefficients ranged from 1.65 to 2.82. The solutions for breed of sire, differences in mean EPD, and regression coefficients are then used to calculate adjustment factors for EPD of 11 breeds including the arbitrary base breed, Angus.

Key words: beef cattle, breed, carcass expected progeny difference, genetic evaluation

(2007 American Society of Animal Science. All rights reserved.

J. Anim. Sci. 2007. 85:1369-1376

doi:10.2527/jas.2006-658

\section{INTRODUCTION}

Notter and Cundiff(1991) developed a method to compare EPD for birth weight, weaning weight, and yearling weight from different breed associations having different base years for use on cows from different breeds. The common base when used with breed association EPD allows a herd owner to compare bulls of many breeds. The original method (Cundiff, 1993) has undergone relatively minor statistical changes. Barkhouse et al. $(1994,1995,1998)$ added random sire and dam effects to obtain more appropriate standard errors

\footnotetext{
${ }^{1}$ The authors express appreciation to Darrell Light for data base support and to Donna White for secretarial support in preparation of this manuscript.

${ }^{2}$ Corresponding author: lvanvleck@unlnotes.unl.edu

Received September 26, 2006.

Accepted February 24, 2007.
}

for breed of sire solutions. In the 1996 analysis, a mixed model, including dam effects, was used to estimate regression of progeny records at USMARC on breed association EPD (Van Vleck and Cundiff, 1996). Van Vleck and Cundiff (2001) used estimates of heterosis from a Hereford by Angus diallel experiment to adjust all progeny records to the basis of $100 \%$ heterozygosity because the purpose of the evaluation is to compare sires of different breeds to produce crossbred calves. Annual updates of across-breed adjustment factors for birth weight, weaning weight, yearling weight, and maternal milk have been available since 1993 (Van Vleck and Cundiff, 2005).

The purpose of this paper is to develop a similar procedure for adjusting breed association EPD to a comparable base for marbling score (MAR), fat thickness (FAT), ribeye area (RIB), and retail product percentage (RPP). The regressions of carcass traits from USMARC steers on breed association EPD were of special interest. 
Table 1. Number of sires $\left(\mathrm{N}_{\mathrm{s}}\right)$ and number of progeny $\left(\mathrm{N}_{\mathrm{p}}\right)$ for each sire breed used in different Cycles of the Germplasm Evaluation Program at the US Meat Animal Research Center that had EPD from breed associations

\begin{tabular}{|c|c|c|c|c|c|c|c|c|c|c|c|c|c|c|c|c|c|c|}
\hline \multirow[b]{3}{*}{ Sire breed } & \multicolumn{16}{|c|}{ Cycle (year of birth) } & & \\
\hline & \multicolumn{2}{|c|}{$(70-72)$} & \multicolumn{2}{|c|}{$(73-74)$} & \multicolumn{2}{|c|}{$(75-76)$} & \multicolumn{2}{|c|}{$(84-90)$} & \multicolumn{2}{|c|}{$(92-94)$} & \multicolumn{2}{|c|}{$(97-98)$} & \multicolumn{2}{|c|}{$(99-00)$} & \multicolumn{2}{|c|}{ (01-02) } & \multicolumn{2}{|c|}{ Total $^{1}$} \\
\hline & $\mathrm{N}_{\mathrm{s}}$ & $\mathrm{N}_{\mathrm{p}}$ & $\mathrm{N}_{\mathrm{s}}$ & $\mathrm{N}_{\mathrm{p}}$ & $\mathrm{N}_{\mathrm{s}}$ & $\mathrm{N}_{\mathrm{p}}$ & $\mathrm{N}_{\mathrm{s}}$ & $\mathrm{N}_{\mathrm{p}}$ & $\mathrm{N}_{\mathrm{s}}$ & $\mathrm{N}_{\mathrm{p}}$ & $\mathrm{N}_{\mathrm{s}}$ & $\mathrm{N}_{\mathrm{p}}$ & $\mathrm{N}_{\mathrm{s}}$ & $\mathrm{N}_{\mathrm{p}}$ & $\mathrm{N}_{\mathrm{s}}$ & $\mathrm{N}_{\mathrm{p}}$ & $\mathrm{N}_{\mathrm{s}}$ & $\mathrm{N}_{\mathrm{p}}$ \\
\hline $\begin{array}{l}\text { Hereford } \\
\text { Angus }\end{array}$ & 5 & 23 & 1 & 1 & 0 & 0 & 22 & 38 & 26 & 91 & 26 & 66 & 20 & 88 & 20 & 94 & 76 & 401 \\
\hline Carcass $^{3}$ & 2 & 9 & 2 & 14 & 2 & 8 & 16 & 40 & 27 & 76 & 22 & 67 & 21 & 94 & 20 & 91 & 68 & 399 \\
\hline Shorthorn & 0 & 0 & 0 & 0 & 0 & 0 & 24 & 96 & 0 & 0 & 0 & 0 & 0 & 0 & 0 & 0 & 24 & 96 \\
\hline Simmental & 25 & 170 & 0 & 0 & 0 & 0 & 0 & 0 & 0 & 0 & 0 & 0 & 20 & 92 & 0 & 0 & 45 & 262 \\
\hline Limousin & 19 & 173 & 0 & 0 & 0 & 0 & 0 & 0 & 0 & 0 & 0 & 0 & 20 & 82 & 0 & 0 & 39 & 255 \\
\hline Charolais & 1 & 8 & 0 & 0 & 0 & 0 & 2 & 3 & 0 & 0 & 0 & 0 & 20 & 89 & 0 & 0 & 23 & 100 \\
\hline Maine-Anjou & 0 & 0 & 13 & 79 & 0 & 0 & 0 & 0 & 0 & 0 & 0 & 0 & 0 & 0 & 0 & 0 & 13 & 79 \\
\hline Gelbvieh & 0 & 0 & 11 & 108 & 0 & 0 & 14 & 86 & 0 & 0 & 0 & 0 & 23 & 89 & 0 & 0 & 48 & 283 \\
\hline
\end{tabular}

${ }^{1}$ Many Hereford and Angus sires were used in more than 1 cycle.

${ }^{2}$ Angus sires with EPD based on ultrasound measurements.

${ }^{3}$ Angus sires with EPD based on carcass measurements.

\section{MATERIALS AND METHODS}

Animal Care and Use Committee approval was not obtained for this study because the data were obtained from an existing database.

Data for these analyses were from steers produced in the Germplasm Evaluation (GPE) Program at the US Meat Animal Research Center whose sires had EPD for carcass traits in recent genetic evaluations of 11 different breeds. The number of sires represented in each breed and the number of progeny they produced in each cycle of the GPE Program are shown in Table 1. The GPE Program has been conducted in 8 cycles to compare topcross performance of 37 sire breeds. Eleven of these breeds have EPD for MAR, FAT, and RIB. The steers were $\mathrm{F}_{1}$ crosses produced from matings to Angus (cycles I to VIII), Hereford (cycles I to VII), and Composite MARC III (cycles V to VIII) dams. Composite MARC III is 25\% each of Angus, Hereford, Red Poll, and Pinzgauer. In cycles I, II, IV, and VII, Hereford and Angus straightbreds, and reciprocal crosses were produced to provide estimates of heterosis.

Hereford and Angus sires were used in each cycle to provide ties for analyses of data pooled over cycles. Some of the Hereford and Angus sires used in cycle I were repeated in cycles II, III, and IV. Ties were also provided in cycles V to VIII by repeated use of Hereford and Angus sires in adjacent cycles of the program. However, only a few Hereford and Angus sires used in cycles I to III had EPD for carcass traits. All of the Simmental, Limousin, Maine-Anjou, and Gelbvieh sires used in cycles I or II of the GPE Program represented foundation sires (sires brought into the United States from Europe) of their breeds in the United States. These foundation sires had breed association EPD for carcass traits as a result of producing progeny for which carcass data were obtained in industry herds. Most of the progeny by Hereford, Angus, Shorthorn, Charolais, Brangus, Salers, and Red Angus sires were in cycles IV to VIII of the GPE Program.

Estimates of heterosis were needed to adjust records to the equivalent of $100 \%$ heterozygosity expected in $\mathrm{F}_{1}$ crosses because offspring from some matings to Hereford, Angus, and Red Angus sires resulted in straightbred Hereford, straightbred Angus, and Red Angus $\times$ Angus progeny with $0 \%$ heterozygosity. Some progeny of Angus, Red Angus, or Hereford sires produced by MARC III composite dams had less than $100 \%$ heterozygosity, as did matings with Brangus (3/8 Brahman, 5/8 Angus) sires. To include more carcass records for estimation of heterosis and to improve ties over the various cycles, the progeny in the Hereford-Angus diallel analysis were not required to have sires with carcass EPD. For example, no estimates of heterosis would have been possible for RPP because no Hereford sires had EPD for RPP. Table 2 describes the analyses for estimating heterosis effects for the 4 traits. Unfortunately, no diallel information was available for breeds other than Hereford and Angus. Estimates from that diallel, however, should be better than no estimates or estimates that confound heterosis and maternal effects.

The second and third steps were to use the records of USMARC progeny adjusted for heterosis to estimate breed of sire effects and coefficients for regression of measurements of USMARC progeny on breed association EPD of their sires. Only progeny of sires with breed association EPD were used in these analyses because, in a later step to account for genetic trend, the breed of sire solutions from USMARC progeny records were adjusted to a current nonparent base (means of EPD 
Table 2. Estimates of heterosis and summary of analyses by trait for the embedded Hereford $\times$ Angus diallel experiment ${ }^{1,2,3}$

\begin{tabular}{|c|c|c|c|c|c|c|c|}
\hline \multirow[b]{2}{*}{ Item } & \multicolumn{2}{|c|}{ Phenotypic } & \multicolumn{2}{|c|}{ Range } & \multicolumn{2}{|c|}{ Heterosis } & \multirow[b]{2}{*}{$t^{2}$} \\
\hline & Mean & $\mathrm{SD}$ & Low & High & Estimate & $\mathrm{SE}$ & \\
\hline Marbling, ${ }^{4}$ score & 5.38 & 0.94 & 3.17 & 9.82 & 0.0204 & 0.0624 & 0.33 \\
\hline Fat thickness, cm & 1.44 & 0.55 & 0.25 & 3.56 & 0.1519 & 0.0353 & 4.32 \\
\hline Ribeye area, $\mathrm{cm}^{2}$ & 71.49 & 8.58 & 46.45 & 101.94 & 2.1795 & 0.5220 & 4.17 \\
\hline Retail product, $\%$ & 63.16 & 3.18 & 50.48 & 72.63 & -0.5637 & 0.2154 & 2.62 \\
\hline
\end{tabular}

${ }^{1}$ Hereford, $\mathrm{n}=189$; Hereford $\times$ Angus, $\mathrm{n}=223$; Angus $\times$ Hereford, $\mathrm{n}=115$; and Angus, $\mathrm{n}=144$.

${ }^{2} t$-statistic for significance of estimate of heterosis.

${ }^{3}$ The model included covariates for weaning age and days on feed; fixed factors (levels) for year (12), age of dam (5), and Hereford $\times$ Angus classes (4); and a random factor for sires ( $\mathrm{n}=400$ for the 3 traits and 138 for retail product).

${ }^{4}$ Nine degrees: from practically devoid (2.0 to 2.9 ) to abundant (10.0 to 10.9$)$.

for animals in breed association genetic evaluations born $2 \mathrm{yr}$ prior to the current analysis of records of USMARC progeny-year 2003 for this study). Table 3 summarizes the available records.

Table 4 lists the average accuracy for $\operatorname{EPD}$ (BIF, 2002) by breed of sire. As expected for carcass traits, these average accuracies were not large and were variable by breed, which contributed to variation in estimates of regression coefficients and of breed of sire effects. Table 5 includes the nonparent (animals born in year 2003) average EPD for the breeds and the average EPD (weighted by number of progeny) for sires of USMARC progeny. The differences in the average EPD were used in a later step.

Estimates within breed of sire of coefficients of regression of USMARC progeny records on breed association EPD of their sires with SE are listed in Table 6. Even with the weight traits, regression coefficients, which were estimated from many more records, were pooled across breeds. Pooled regression coefficients are shown in Table 7. With the carcass data, pooling was also by type of measurement used for the breed association EPD. Hereford and Brangus EPD were based on ultrasound measurements. The other EPD, except for Angus, were based on traditional carcass measurements. The American Angus Association furnished separate EPD based on ultrasound and traditional carcass measurements as indicated in Table 7. Because of the relatively large number of Angus progeny, the pooled regression coefficients chosen for later use included those from analyses of Angus progeny at USMARC with the traditional or ultrasound EPD of their sires.

Once the appropriate regression coefficients and breed of sire effects were estimated, the next step was to adjust the breed of sire effects, which were based on samples of sires (and for some breeds over a long period of time), to that which would be expected if the sample of sires had been from animals born in the nonparent year chosen as a base year. The adjustment to the conditions and units of measurement for the USMARC progeny used the difference between the average EPD for the nonparent year and average EPD of sires of the USMARC progeny multiplied by the appropriate regression coefficient.

For example, let MARC(i) be the solution for breed of sire i from records of USMARC progeny. Let EPDyyi be the mean EPD for the nonparent year (yy) for breed $i$ and EPDi be the mean EPD for sires of progeny with records at USMARC weighted by number of progeny. The regression coefficient used to adjust the MARC solution depends on whether the corresponding EPD was based on traditional carcass measurements $\left(b_{c}\right)$ or ultrasound measurements $\left(b_{u}\right)$.

For breed A with ultrasound EPD, the adjusted breed of sire solution is

$$
\operatorname{MARC}(\mathrm{A}, \operatorname{adj})=\operatorname{MARC}(\mathrm{A})+\mathrm{b}_{\mathrm{u}}(\overline{\mathrm{EPD}} \mathrm{yy} \mathrm{A}-\overline{E P D} A) .
$$

For breed B with traditional carcass EPD, the adjusted breed of sire solution is

Table 3. Unadjusted means and SD and ranges for individuals, and averages for breed of sire by trait

\begin{tabular}{|c|c|c|c|c|c|c|}
\hline \multirow[b]{2}{*}{ Item } & \multicolumn{2}{|c|}{ Phenotypic } & \multicolumn{2}{|c|}{ Individual range } & \multicolumn{2}{|c|}{ Breed range } \\
\hline & Mean & $\mathrm{SD}$ & Low & High & Low & High \\
\hline Marbling, ${ }^{1}$ score & 5.29 & 0.83 & 2.82 & 9.52 & 4.93 & 5.90 \\
\hline Fat thickness, cm & 1.14 & 0.51 & 0.13 & 3.33 & 0.89 & 1.37 \\
\hline Ribeye area, $\mathrm{cm}^{2}$ & 80.59 & 9.10 & 49.68 & 127.75 & 72.97 & 87.68 \\
\hline Retail product, $\%$ & 63.77 & 3.18 & 52.51 & 73.12 & 62.83 & 64.56 \\
\hline
\end{tabular}

${ }^{1}$ Nine degrees: from practically devoid (2.0 to 2.9 ) to abundant (10.0 to 10.9 ). 
Table 4. Weighted means of accuracy of EPD (BIF) by breed of sire for sires of progeny with carcass measurements at USMARC for marbling score (MAR), fat thickness (FAT), ribeye area (RIB), and retail product percentage (RPP)

\begin{tabular}{|c|c|c|c|c|c|c|}
\hline \multirow[b]{2}{*}{ Sire breed } & \multicolumn{2}{|c|}{ No. } & \multicolumn{4}{|c|}{ Trait } \\
\hline & Sires & Progeny & MAR & FAT & RIB & $\mathrm{RPP}$ \\
\hline Hereford & 76 & 401 & 0.25 & 0.29 & 0.28 & - \\
\hline Angus $^{1}$ & 80 & 450 & 0.46 & 0.46 & 0.46 & 0.46 \\
\hline Angus $^{2}$ & 68 & 399 & 0.50 & 0.44 & 0.46 & 0.45 \\
\hline Shorthorn & 24 & 96 & 0.24 & 0.25 & 0.23 & 0.24 \\
\hline Simmental & 45 & 262 & 0.68 & 0.68 & 0.68 & - \\
\hline Limousin & 39 & 255 & 0.63 & 0.68 & 0.64 & - \\
\hline Charolais & 23 & 99 & 0.43 & 0.44 & 0.46 & - \\
\hline Maine-Anjou & 13 & 79 & 0.28 & 0.28 & 0.28 & 0.27 \\
\hline Gelbvieh & 48 & 283 & 0.48 & 0.46 & 0.49 & - \\
\hline Brangus & 21 & 104 & 0.45 & 0.48 & 0.52 & - \\
\hline Salers & 23 & 84 & 0.17 & 0.26 & 0.24 & 0.21 \\
\hline Red Angus & 20 & 90 & 0.61 & 0.50 & 0.59 & - \\
\hline
\end{tabular}

${ }^{1}$ Angus sires with EPD based on ultrasound (\% intramuscular fat for marbling) measurements.

${ }^{2}$ Angus sires with EPD based on traditional carcass measurements.

$$
\operatorname{MARC}(B, \operatorname{adj})=\operatorname{MARC}(B)+b_{c}(\overline{\operatorname{EPD}} y y B-\overline{E P D} B) .
$$

For sire $\mathrm{m}$ of breed $\mathrm{A}$, the difference from EPDyyA can be represented as

$$
E P D(A, m)-\overline{E P D} y y A .
$$

As a difference on the USMARC scale of measurement and to the common base year, the adjusted difference in EPD from $\overline{E P D} y y A$ is

$$
\begin{gathered}
\operatorname{MARC}(\mathrm{A}, \mathrm{m}, \mathrm{adj})=\operatorname{MARC}(\mathrm{A}, \mathrm{adj}) \\
+\mathrm{b}_{\mathrm{u}}[E P D(A, m)-\overline{E P D} y y A] .
\end{gathered}
$$

For sire $\mathrm{n}$ of breed $\mathrm{B}$, the adjusted difference in EPD is

$$
\begin{gathered}
\operatorname{MARC}(\mathrm{B}, \mathrm{n}, \mathrm{adj})=\operatorname{MARC}(\mathrm{B}, \mathrm{adj}) \\
+\mathrm{b}_{\mathrm{c}}[E P D(B, n)-\overline{E P D} y y B] .
\end{gathered}
$$

Thus, MARC(A,m,adj) and MARC(B,n,adj) can be compared on the USMARC scale of measurement and to a common base year (yy).

For the weight traits, a regression coefficient of unity was assumed for the last step for all breeds. To construct a table of adjustment factors, 1 breed was usually chosen as a base. For example, the adjusted EPD for sire $\mathrm{p}$ of breed $\mathrm{X}$ would be

$$
\begin{gathered}
\operatorname{MARC}(\mathrm{X}, \mathrm{p}, \mathrm{adj})=\operatorname{MARC}(\mathrm{X}, \mathrm{adj}) \\
+\mathrm{b}_{\mathrm{x}}[E P D(X, p)-\overline{E P D} y y X]
\end{gathered}
$$

with $b_{\mathrm{x}}$ either $b_{\mathrm{c}}$ or $\mathrm{b}_{\mathrm{u}}$.

Table 5. Total number of progeny and weighted means of expected progeny differences (EPD) by breed of sire for sires of progeny with carcass measurements at USMARC, and nonparent mean EPD from breed associations

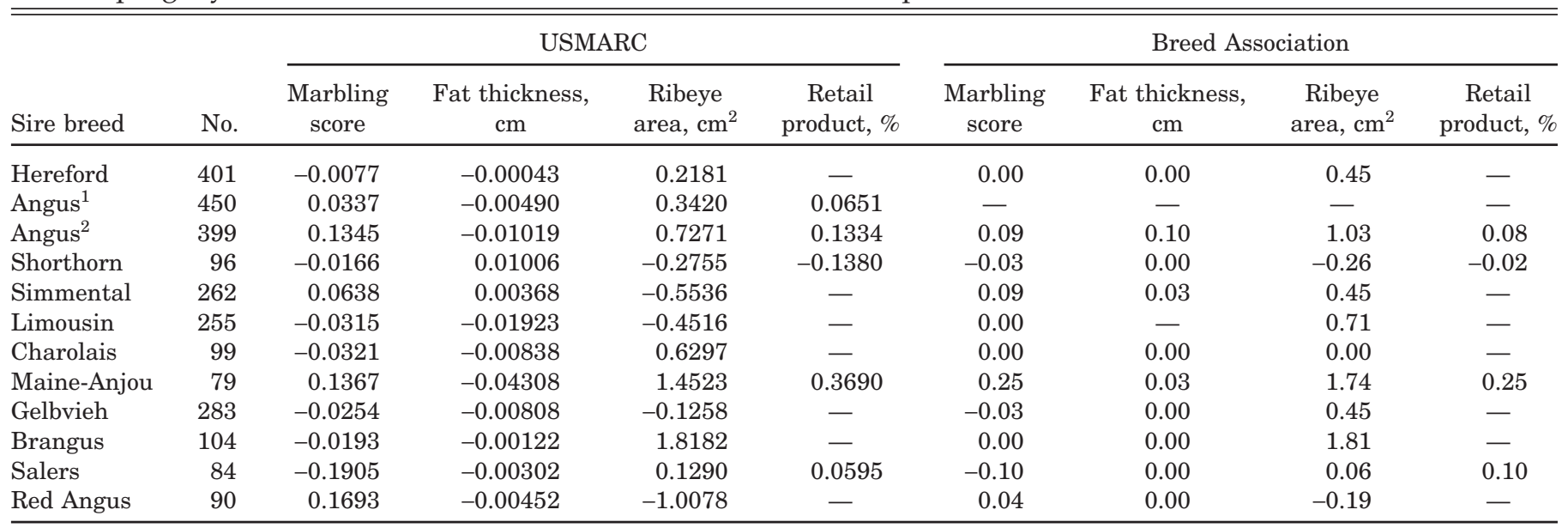

${ }^{1}$ Progeny with Angus sires having EPD based on ultrasound (\% intramuscular fat for marbling) measurements.

${ }^{2}$ Progeny with Angus sires having EPD based on traditional carcass measurements. 
Table 6. Regression coefficients $( \pm S E)$ within breed of sire by trait of progeny measurements ${ }^{1}$ at USMARC on breed association EPD for Angus progeny having sires with EPD based on ultrasound measurements or on traditional carcass measurements ${ }^{2}$

\begin{tabular}{|c|c|c|c|c|c|c|c|c|}
\hline Sire breed & \multicolumn{4}{|c|}{ With ultrasound Angus EPD } & \multicolumn{4}{|c|}{ With traditional carcass Angus EPD } \\
\hline Hereford & $1.11 \pm 0.38$ & $2.83 \pm 0.61$ & $0.61 \pm 0.46$ & - & $0.98 \pm 0.38$ & $2.72 \pm 0.62$ & $0.60 \pm 0.46$ & - \\
\hline Shorthorn & $2.04 \pm 0.42$ & $2.31 \pm 0.65$ & $1.66 \pm 0.77$ & $2.11 \pm 0.59$ & $2.01 \pm 0.42$ & $2.34 \pm 0.65$ & $1.65 \pm 0.77$ & $2.18 \pm 0.59$ \\
\hline Simmental & $0.52 \pm 0.32$ & $0.77 \pm 0.75$ & $1.37 \pm 0.40$ & - & $0.50 \pm 0.32$ & $0.94 \pm 0.76$ & $1.44 \pm 0.40$ & - \\
\hline Limousin & $2.06 \pm 0.52$ & $1.13 \pm 0.44$ & $1.09 \pm 0.29$ & - & $2.05 \pm 0.52$ & $1.22 \pm 0.44$ & $1.12 \pm 0.29$ & - \\
\hline Gelbvieh & $1.78 \pm 0.37$ & $1.95 \pm 0.52$ & $1.81 \pm 0.31$ & - & $1.81 \pm 0.37$ & $2.02 \pm 0.53$ & $1.79 \pm 0.31$ & - \\
\hline Brangus & $3.74 \pm 0.75$ & $0.62 \pm 2.14$ & $0.86 \pm 0.46$ & - & $3.72 \pm 0.76$ & $0.58 \pm 2.15$ & $0.88 \pm 0.46$ & - \\
\hline Salers & $0.34 \pm 0.25$ & $1.25 \pm 2.09$ & $4.24 \pm 1.69$ & $2.15 \pm 2.49$ & $0.32 \pm 0.25$ & $1.07 \pm 2.10$ & $4.30 \pm 1.69$ & $2.26 \pm 2.48$ \\
\hline Red Angus & $1.01 \pm 0.29$ & $3.66 \pm 1.04$ & $1.89 \pm 0.60$ & - & $1.01 \pm 0.29$ & $3.64 \pm 1.04$ & $1.89 \pm 0.60$ & - \\
\hline
\end{tabular}

${ }^{1} \mathrm{MAR}=$ marbling score; $\mathrm{FAT}=$ fat thickness, $\mathrm{cm} ; \mathrm{RIB}=$ ribeye area, $\mathrm{cm}^{2} ; \mathrm{RPP}=$ retail product, $\%$.

${ }^{2}$ Hereford and Brangus EPD were based on ultrasound measurements in all analyses.

${ }^{3}$ The American Angus Association last published RPP EPD for carcass or ultrasound in 2005.

The constant parts of the differences in EPD of sires of breeds A, B, and $\mathrm{X}$ determine the across-breed adjustment factors with breed $\mathrm{X}$ chosen as the base breed. The difference between adjusted EPD for sire $m$ of breed $\mathrm{A}$ and sire $\mathrm{p}$ of base breed $\mathrm{X}$ is

$$
\begin{array}{r}
\text { MARC }(A, \operatorname{adj})+\mathrm{b}_{\mathrm{u}}[E P D(A, m)-\overline{E P D} y y A] \\
-\operatorname{MARC}(\mathrm{X}, \operatorname{adj})+\mathrm{b}_{\mathrm{x}}[E P D(X, p)-\overline{E P D} y y X] .
\end{array}
$$

Rearrangement from combining the constant parts and EPD of individual sires of the difference results in

$$
\begin{gathered}
{[\operatorname{MARC}(\mathrm{A}, \operatorname{adj})-\operatorname{MARC}(\mathrm{X}, \mathrm{adj})]} \\
-\left[b_{u} \overline{\operatorname{EPD}} y \mathrm{~A}-b_{x} \overline{E P D} y y X\right]+\mathrm{b}_{\mathrm{u}} \operatorname{EPD}(\mathrm{A}, \mathrm{m})-\mathrm{b}_{\mathrm{x}} \operatorname{EPD}(\mathrm{X}, \mathrm{p}) .
\end{gathered}
$$

The sum of the 2 square brackets will be the constant adjustment factor to compare sires of breed $\mathrm{A}$ and sires of breed X. Let that sum be $\mathrm{ADJ}(\mathrm{A}-\mathrm{X})$.

In contrast to adjustment factors for the weight traits, each of the $\overline{E P D}_{y y}$ was multiplied by the regres- sion coefficient, which converted the units for $\overline{E P D}_{y y}$ to the units used for measuring the USMARC progeny.

When comparing EPD of individual sires of breed A and breed X, the EPD was also converted to the USMARC scale of measurement by the corresponding regression coefficient.

Similarly, the constant adjustment factor to compare sires of breed B with sires of breed X was

$$
\begin{gathered}
\operatorname{ADJ}(\mathrm{B}-\mathrm{X})=[\operatorname{MARC}(\mathrm{B}, \operatorname{adj})-\operatorname{MARC}(\mathrm{X}, \operatorname{adj})] \\
-\left[b_{c} \overline{\operatorname{EPD}} y y B-b_{x} \overline{E P D} y y X\right] .
\end{gathered}
$$

Comparison of EPD for sire $n$ of breed B with sire $p$ of breed X was

$$
\mathrm{ADJ}(\mathrm{B}-\mathrm{X})+\mathrm{b}_{\mathrm{c}} \operatorname{EPD}(\mathrm{B}, \mathrm{n})-\mathrm{b}_{\mathrm{x}} \operatorname{EPD}(\mathrm{X}, \mathrm{p}) .
$$

Comparison of EPD for sire $\mathrm{m}$ of breed A and EPD of sire $\mathrm{n}$ of breed B yields

Table 7. Pooled estimates of coefficients of regression ( \pm SE) of carcass measurements of progeny ${ }^{1}$ at USMARC on breed association EPD based on ultrasound or traditional carcass measurements

\begin{tabular}{lcccc}
\hline \hline & \multicolumn{4}{c}{ Trait } \\
\cline { 2 - 5 } EPD $^{2}$ & MAR & FAT & RIB & RPP $^{3}$ \\
\hline CAR, with Angus & $0.9206 \pm 0.1014$ & $1.6694 \pm 0.1870$ & $1.6527 \pm 0.1498$ & $2.0596 \pm 0.2800$ \\
CAR, no Angus & $0.9990 \pm 0.1316$ & $1.7285 \pm 0.2578$ & $1.5542 \pm 0.1711$ & $2.2417 \pm 0.5762$ \\
US, with Angus & $1.0743 \pm 0.1669$ & $2.8162 \pm 0.3508$ & $0.8791 \pm 0.1926$ & $2.3468 \pm 0.4533$ \\
US, no Angus & $1.5377 \pm 0.3416$ & $2.6063 \pm 0.5923$ & $0.7461 \pm 0.3251$ & - \\
\hline
\end{tabular}

${ }^{1} \mathrm{MAR}=$ marbling score FAT $=$ fat thickness, $\mathrm{cm} ; \mathrm{RIB}=$ ribeye area, $\mathrm{cm}^{2} ; \mathrm{RPP}=$ retail product, $\%$.

${ }^{2} \mathrm{CAR}$, with Angus = pools all breeds including Angus, except Hereford and Brangus, for EPD based on traditional carcass measurements; CAR, no Angus = pools all breeds, except Angus, Hereford, and Brangus, for EPD based on traditional carcass measurements; US, with Angus = pools Angus, Hereford, and Brangus for EPD based on ultrasound measurements with Angus based on \% intramuscular fat; US, no Angus = pools Hereford and Brangus for EPD based on ultrasound measurements.

${ }^{3} \mathrm{RPP}$ included only Angus, Shorthorn, Maine-Anjou, and Salers; as of 2006, Angus no longer reports RPP. 


$$
\operatorname{ADJ}(A-X)-A D J(B-X)+b_{u} \operatorname{EPD}(A, m)-b_{c} \operatorname{EPD}(B, n) .
$$

Comparison of EPD for pairs of sires, $s$ and $t$, for the same breed (e.g., breed A) yields

$$
\operatorname{ADJ}(\mathrm{A}-\mathrm{X})-\mathrm{ADJ}(\mathrm{A}-\mathrm{X})+\mathrm{b}_{\mathrm{u}} \operatorname{EPD}(\mathrm{A}, \mathrm{s})-\mathrm{b}_{\mathrm{u}} \operatorname{EPD}(\mathrm{A}, \mathrm{t}) .
$$

The first 2 terms (adjustment factors) cancel. The regression coefficient, $b_{u}$, is not necessary for the comparison, but does convert the EPD for breed A to the USMARC scale of measurement.

To make a table of adjustment factors, the appropriate regression coefficient $\left(b_{u}\right.$ or $\left.b_{c}\right)$ was needed for each breed, including the base breed.

Conversion of adjusted EPD to a measurement scale other than that used at USMARC would be easy. Perhaps the easiest way is to make the comparisons as described above and then divide by $b_{u}$ if adjusted EPD on the ultrasound scale are desired or by $b_{c}$ for adjusted EPD on the traditional carcass scale.

Derivation of an equivalent set of adjustment factors does not require the mean breed association EPD for year yy. For example, examining the terms in the comparison of EPD for breeds A and X by expanding the parts of MARC(A,adj) and MARC(X,adj) yields

$$
\begin{gathered}
\left\{\text { MARC }(A)+b_{u}\left[\overline{\operatorname{EPD}}_{y y A}-\overline{\operatorname{EPD}}_{\mathrm{A}}\right]\right. \\
\left.+b_{\mathrm{u}}\left[\mathrm{EPD}(\mathrm{A}, \mathrm{m})-\overline{\mathrm{EPD}}_{\mathrm{yyA}}\right]\right\} \\
-\left\{\mathrm{MARC}^{\mathrm{M}} \mathrm{X}\right)+\mathrm{b}_{\mathrm{x}}\left[\overline{\mathrm{EPD}}_{\mathrm{yyX}}-\overline{\mathrm{EPD}}_{\mathrm{X}}\right] \\
\left.+\mathrm{b}_{\mathrm{x}}\left[\mathrm{EPD}(\mathrm{X}, \mathrm{p})-\overline{\mathrm{EPD}}_{\mathrm{yyX}}\right]\right\} .
\end{gathered}
$$

The $\overline{\mathrm{EPD}}_{\mathrm{yyA}}$ and $\overline{\mathrm{EPD}}_{\mathrm{yyx}}$ terms cancel so that the remaining terms are

$$
\begin{gathered}
{[\operatorname{MARC}(A)-\operatorname{MARC}(\mathrm{X})]-\left[\mathrm{b}_{\mathrm{u}} \overline{\operatorname{EPD}}_{\mathrm{A}}-\mathrm{b}_{\mathrm{x}} \overline{\operatorname{EPD}}_{\mathrm{X}}\right]} \\
+\left[\mathrm{b}_{\mathrm{u}} \operatorname{EPD}(\mathrm{A}, \mathrm{m})-\mathrm{b}_{\mathrm{x}} \operatorname{EPD}(\mathrm{X}, \mathrm{p})\right] .
\end{gathered}
$$

Thus, the adjustment factor, $\mathrm{ADJ}(\mathrm{A}-\mathrm{X})$ for comparing EPD of breeds A and X is the sum of the terms in the first 2 brackets:

$$
\begin{gathered}
\operatorname{ADJ}(\mathrm{A}-\mathrm{X})=[M A R C(A)-\operatorname{MARC}(\mathrm{X})] \\
-\left[b_{u} \overline{E P D} A-b_{x} \overline{E P D} X\right] .
\end{gathered}
$$

Similarly, the adjustment factor for breeds B and X is

$$
\begin{gathered}
\operatorname{ADJ}(\mathrm{B}-\mathrm{X})=[\operatorname{MARC}(\mathrm{B})-\operatorname{MARC}(\mathrm{X})] \\
-\left[\mathrm{b}_{\mathrm{c}} \overline{\mathrm{EPDB}}-\mathrm{b}_{\mathrm{x}} \overline{\mathrm{EPD} X}\right] .
\end{gathered}
$$

This derivation shows that the average EPD for nonparents (year yy) is not needed, but the logic of the adjustment is not as clear.

\section{RESULTS AND DISCUSSION}

The within-breed of sire estimates of coefficients for regression of measurements of USMARC progeny on
EPD of their sires in Table 6 are variable and have large standard errors. The estimates for the 2 analyses that included progeny of Angus sires with EPD based on ultrasound or traditional carcass measurement are generally similar, as would be expected, given that the same source of measurement was used for most breeds. What is distinctive is the difference in regression coefficients within the Angus breed of sire. The coefficients for regression of progeny on EPD were similar for MAR (0.90 and 0.82 ) for the 2 analyses, but were quite different for the other 3 traits, with differences in coefficients of regression exceeding even the large SE ( 2.89 vs. 1.53 for FAT; 0.95 vs. 1.93 for RIB; and 2.35 vs. 1.98 for retail product).

Pooled estimates of regression coefficients for all breeds with EPD based on traditional carcass measurements and with EPD based on ultrasound measurements are shown in Table 7. The estimates for the 2 analyses including Angus with other breeds having ultrasound EPD and with other breeds having EPD based on traditional carcass measures show similarity for MAR (1.0743 vs. 0.9206), considerable difference for FAT (2.8162 vs. 1.6694 ) and for RIB (0.8791 vs. 1.6527$)$, and less difference with large SE for RPP (2.3468 vs. 2.0596). Thus, use of different coefficients of regression with EPD based on ultrasound measurements and with EPD based on traditional carcass measurements seems appropriate, especially for FAT and RIB, although for consistency in this project, regression coefficients used for MAR and RPP also were based on type of measurement used for EPD. The regression coefficients indicate that selection based on EPD for carcass traits can be effective in changing carcass traits in steers produced in commercial production systems. The fact that regression coefficients for FAT and RPP were significantly greater than 1.0 was not surprising because bulls and replacement heifers are not fed and finished to the same degree of fatness as steers fed for slaughter. Under these circumstances, the regression coefficients of approximate unity for MAR may suggest a need to improve estimation of breeding values for MAR. Nevertheless, the regression coefficients of near unity for MAR indicate that selection based on EPD calculated primarily from ultrasound measurements on live yearling bulls and heifers developed for breeding can impact profitability of beef production by increasing marbling, which is an important determinant of beef carcass value in domestic and export markets.

Thus far, differences between mean EPD for sires with USMARC progeny and mean nonparent EPD for a given base year (e.g., yy) and regression coefficients for adjusting breed differences at USMARC to a year yy basis have been described and estimated. The last link in the path to across-breed adjustment factors is estimation of breed of sire differences from carcass measurements of progeny at USMARC having sires with breed association EPD. Table 8 lists breed of sire solutions for the 4 carcass traits as differences from Angus for the 2 sets of analyses (differing only by which Angus 
Table 8. Breed of sire solutions ${ }^{1}$ as a difference from Angus for carcass measurements of progeny ${ }^{2}$ at USMARC, with the $F$-statistic for test of differences among breeds $(P<0.001$ for all columns) ${ }^{3}$

\begin{tabular}{lccccccccc}
\hline \hline & \multicolumn{3}{c}{ With ultrasound Angus EPD } & & \multicolumn{3}{c}{ With traditional carcass Angus EPD } \\
\cline { 2 - 3 } Sire breed & MAR & FAT & RIB & RPP & & MAR & FAT & RIB & RPP \\
\hline Hereford & -0.4461 & -0.0952 & -1.5491 & - & -0.5151 & -0.1196 & -1.3472 & - \\
Angus $^{4}$ & 0.0000 & 0.0000 & 0.0000 & 0.0000 & & 0.0000 & 0.0000 & 0.0000 & 0.0000 \\
Shorthorn & 0.0422 & -0.3147 & -1.3530 & 0.9232 & & 0.0026 & -0.3053 & -0.7239 & 1.0581 \\
Simmental & -0.4695 & -0.5491 & 4.9042 & - & -0.6087 & -0.5933 & 4.9706 & - \\
Limousin & -0.7622 & -0.5212 & 7.9463 & - & -0.9018 & -0.5662 & 8.0089 & - \\
Charolais & -0.5630 & -0.6165 & 5.7010 & - & -0.6551 & -0.6434 & 5.9610 & - \\
Maine-Anjou & -0.6031 & -0.6634 & 5.7094 & 3.5833 & -0.8047 & -0.7117 & 7.0830 & 4.6971 \\
Gelbvieh & -0.6102 & -0.6076 & 4.1499 & - & -0.7323 & -0.6312 & 4.8603 & - \\
Brangus & -0.6193 & -0.3101 & 3.1724 & - & -0.6747 & -0.3221 & 3.3047 & - \\
Salers & -0.4411 & -0.5146 & 4.1428 & 2.7155 & -0.4703 & -0.5080 & 4.8603 & 2.8670 \\
Red Angus & 0.1234 & -0.1118 & -2.2485 & - & & 0.0318 & -0.1382 & -2.0246 & - \\
$F$-statistic & 16.98 & 27.76 & 17.72 & 10.12 & 19.40 & 28.87 & 18.13 & 12.96 \\
\hline
\end{tabular}

${ }^{1}$ On left when Angus progeny had sires with ultrasound EPD and on right when Angus progeny had sires with traditional carcass EPD.

${ }^{2} \mathrm{MAR}=$ marbling $\mathrm{score} ; \mathrm{FAT}=$ fat thickness, $\mathrm{cm} ; \mathrm{RIB}=$ ribeye area, $\mathrm{cm}^{2} ; \mathrm{RPP}=$ retail product, $\%$.

${ }^{3}$ Model for analyses included covariates for weaning age and days on feed; fixed factors (levels) for breed of sire (11), breed of dam (3), year of birth (21), and age of dam classes (5); and uncorrelated and random factors of sires and dams.

${ }^{4}$ Angus ultrasound marbling score EPD was based on \% intramuscular fat.

progeny are included: those with sires having EPD based on ultrasound measurements or those with sires having EPD based on traditional carcass measurements). The model used for the analyses is given as a footnote. The $F$-statistics for testing whether all breeds of sire are equal are also given, computed from breed of sire solutions after adjusting for all other factors in the model. Differences in estimates are considerable for some pairs of breeds. These differences, however, are not really comparable because samples of sires come from different periods of time and samples of sires among breeds differ even for the same time period.

The next step is to adjust the sample of sires for each breed to a common base (year yy) using the regression coefficients and differences between the sample of bulls used at USMARC (mean EPD weighted by number of progeny) and the breed average EPD for the base year (year yy). These steps were illustrated symbolically earlier and made use of the coefficients of regression to adjust the change from the sample of sires used at USMARC to the population in year yy. For example, for breed A,

$$
\operatorname{MARC}(A, a d j)=\operatorname{MARC}(A)+b(\overline{E P D} y y A-\overline{E P D} A),
$$

where the regression coefficient $\mathrm{b}$ (for ultrasound or traditional carcass EPD) adjusts the change to conditions at USMARC.

The steps described earlier to create adjustment factors to allow comparison of EPD of different breeds were

Table 9. Across-breed adjustment factors with an Angus base for carcass measurements of progeny ${ }^{1}$ of Angus sires with EPD based on ultrasound measurements or on traditional carcass measurements

\begin{tabular}{|c|c|c|c|c|c|c|c|c|}
\hline \multirow[b]{2}{*}{ Sire breed } & \multicolumn{4}{|c|}{ With ultrasound Angus EPD } & \multicolumn{4}{|c|}{ With traditional carcass Angus EPD } \\
\hline & MAR & FAT & RIB & $\mathrm{RPP}$ & MAR & FAT & RIB & $\mathrm{RPP}$ \\
\hline Hereford & -0.4016 & -0.1080 & -1.4401 & - & -0.3830 & -0.1354 & -0.3374 & - \\
\hline Angus $^{2}$ & 0.0000 & 0.0000 & 0.0000 & 0.0000 & 0.0000 & 0.0000 & 0.0000 & 0.0000 \\
\hline Shorthorn & 0.0937 & -0.3452 & -0.5968 & 1.3602 & 0.1417 & -0.3391 & 0.9265 & 1.6171 \\
\hline Simmental & -0.4920 & -0.5692 & 6.1197 & - & -0.5436 & -0.6165 & 7.0875 & - \\
\hline Limousin & -0.6970 & -0.5029 & 8.9934 & - & -0.7490 & -0.5512 & 9.9567 & - \\
\hline Charolais & -0.4972 & -0.6162 & 4.9609 & - & -0.5017 & -0.6464 & 6.1223 & - \\
\hline Maine-Anjou & -0.6927 & -0.6053 & 3.6099 & 2.9761 & -0.8067 & -0.6568 & 5.8842 & 4.2119 \\
\hline Gelbvieh & -0.5506 & -0.6078 & 4.6583 & - & -0.5851 & -0.6347 & 6.2701 & - \\
\hline Brangus & -0.5624 & -0.3205 & 1.8750 & - & -0.5301 & -0.3355 & 2.9079 & - \\
\hline Salers & -0.2295 & -0.5232 & 4.2299 & 2.7457 & -0.1711 & -0.5199 & 5.8810 & 3.0192 \\
\hline Red Angus & 0.0037 & -0.1181 & -0.2826 & - & -0.0002 & -0.1476 & 0.8426 & - \\
\hline
\end{tabular}

${ }^{1} \mathrm{MAR}=$ marbling score FAT $=$ fat thickness, $\mathrm{cm} ; \mathrm{RIB}=$ ribeye area, $\mathrm{cm}^{2} ; \mathrm{RPP}=$ retail product, $\%$.

${ }^{2}$ Angus ultrasound marbling score was based on \% intramuscular fat. 
Table 10. Estimates of variance components from carcass measurements of progeny of sires with breed association $\mathrm{EPD}^{1.2}$

\begin{tabular}{lcrrr}
\hline \hline & \multicolumn{4}{c}{ Trait $^{3}$} \\
\cline { 2 - 5 } Component & MAR & FAT & \multicolumn{1}{c}{ RIB } & RPP \\
\hline Sire/breed & 0.0498 & 0.0231 & 6.3433 & 1.1887 \\
Dam/breed & 0.0603 & 0.0152 & 4.2072 & 0.0006 \\
Residual & 0.3931 & 0.1239 & 43.6087 & 6.4641 \\
Total & 0.5032 & 0.1610 & 54.1589 & 7.6534 \\
\hline
\end{tabular}

${ }^{1}$ Model for analysis included covariates for weaning age and days on feed; fixed factors (levels) for breed of sire (11); breed of dam (3); year of birth (21), and age of dam classes (5); and uncorrelated random factors of sires and dams.

${ }^{2}$ Included Angus progeny of sires with EPD from ultrasound measurements (estimates including Angus progeny of sires with EPD from traditional measurements were similar).

${ }^{3} \mathrm{MAR}=$ marbling score; FAT $=$ fat thickness, $\mathrm{cm} ; \mathrm{RIB}=$ ribeye area, $\mathrm{cm}^{2} ; \mathrm{RPP}=$ retail product, $\%$.

followed to obtain Table 9 . The adjustment factors are relative to the Angus breed. Because, for this study, Angus EPD were available based on ultrasound or traditional carcass measurements, 2 sets of factors are shown. The 2 sets of factors are somewhat different because of 1) the difference in the source of Angus information (e.g., there were some differences in Angus sired progeny measured at USMARC, which makes acrossbreed comparisons at USMARC somewhat different), 2) different information included in the Angus EPD (ultrasound and carcass), and 3) the different coefficients of regression for Angus EPD depending on whether the EPD were based on ultrasound or traditional carcass measurements. Generally, the acrossbreed adjustment factors are similar to the breed of sire solutions because the differences in mean EPD between sires of progeny at USMARC and the mean nonparent EPD for the breed associations were small with few exceptions.

Table 10 contains estimates of variance components for carcass measures from the same analyses used to estimate breed of sire effects. The within-breed estimates of sire components for MAR, FAT, RIB, and RPP correspond to heritability estimates of $0.40,0.57,0.47$, and 0.62 , respectively, which indicate selection for these traits should be effective when EPD become generally available. Standard errors for estimates of heritability were 0.08 , except 0.16 for RPP.

In conclusion, differences exist among breeds of sire for the carcass traits of MAR, FAT, RIB, and RPP. These traits also exhibit genetic variation in progeny raised under USMARC conditions. Pooled coefficients of regression of traits measured on progeny under USMARC conditions on breed association EPD are significant, indicating that selection within breeds based on EPD for carcass traits determined from ultrasound measurements on yearling bulls and heifers in seedstock herds or traditional carcass measurements on steers can be used to increase marbling, reduce FAT, and increase RIB in steers produced for slaughter in commercial production systems. Commercial producers can use the across-breed adjustment factors, based on ultrasound or traditional carcass measurement, to compare sires of the 11 breeds studied for use on cows of other breeds. As with across-breed factors for weight traits, standard errors of differences between sires of different breeds could be calculated, but the magnitude of the standard errors will tend to be associated with the within-breed accuracies of genetic evaluation.

\section{LITERATURE CITED}

Barkhouse, K. L., L. D. Van Vleck, and L. V. Cundiff. 1994. Breed comparisons for growth and maternal traits adjusted to a 1992 base. Pages 197-209 in Proc. BIF Res. Symp., Des Moines, IA. Beef Improv. Fed., Manhattan, KS.

Barkhouse, K. L., L. D. Van Vleck, and L. V. Cundiff. 1995. Mixed model methods to estimate breed comparisons for growth and maternal traits adjusted to a 1993 base. Pages 218-239 in Proc. BIF Res. Symp., Sheridan, WY. Beef Improv. Fed., Manhattan, KS.

Barkhouse, K. L., L. D. Van Vleck, and L. V. Cundiff. 1998. Effect of ignoring random sire and dam effects on estimates and standard errors of breed comparisons. J. Anim. Sci. 76:2279-2286.

Beef Improvement Federation. 2002. Guidelines for Uniform Beef Improvement Programs. 8th ed. Dep. Anim. Dairy Sci., Univ. Georgia, Athens.

Cundiff, L. V. 1993. Breed comparisons adjusted to a 1991 basis using current EPD's. Pages 114-123 in Proc. BIF Res. Symp., Asheville, NC. Beef Improv. Fed., Manhattan, KS.

Notter, D. R., and L. V. Cundiff. 1991. Across-breed expected progeny differences: Use of within-breed expected progeny differences to adjust breed evaluations for sire sampling and genetic trend. J. Anim. Sci. 69:4763-4776.

Van Vleck, L. D., and L. V. Cundiff. 1996. The across-breed EPD tables adjusted to a 1994 base. Pages 130-145 in Proc. Beef Improv. Fed. 28th Res. Symp., Birmingham, AL. Beef Improv. Fed., Manhattan, KS.

Van Vleck, L. D., and L. V. Cundiff. 2001. Across-breed EPD tables for 2001 adjusted to breed differences for birth year 1999. Pages 44-63 in Proc. Beef Improv. Fed. Res. Symp. Annu. Meet., San Antonio, TX. Beef Improv. Fed., Manhattan, KS.

Van Vleck, L. D., and L. V. Cundiff. 2005. Across-breed EPD tables for the year 2005 adjusted to breed differences for birth year of 2003. Pages 126-142 in Beef Improv. Fed. Res. Annu. Meet., Billings, MT. Beef Improv. Fed., Manhattan, KS. 